\title{
Covid-19 and heuristic biases: evidence from India
}

\author{
Shashank Kathpal ${ }^{1,2} \cdot$ Asif Akhtar $^{3} \cdot$ Asma Zaheer $^{4} \cdot$ Mohd Naved Khan $^{5}$
}

Received: 18 February 2021 / Revised: 23 June 2021 / Accepted: 31 August 2021 / Published online: 27 October 2021

(c) The Author(s), under exclusive licence to Springer Nature Limited 2021

\begin{abstract}
Stock markets worldwide have witnessed high volatility during the year 2020 owing to the eruption of Covid-19. Due to the world's unprecedented economic challenges, this study could potentially guide financial advisors and individual investors in dealing with pandemics. An association between investors' perception toward the intensity of Covid-19 and heuristic biases is analyzed using the responses of 290 stock investors of National Capital Region (NCR), India. The data are validated through Cronbach's alpha, and the model fit is analyzed using EFA. Confirmatory factor analysis (CFA) is employed to investigate the relationship between Covid-19 and heuristic biases. Covid-19 does not have any influence on the overconfidence of investors. A significant positive relationship is found between Covid-19 and the remaining three heuristics, i.e., availability, anchoring, and representativeness. The present study analyzes the association between Covid-19 and specific investors' bias only and should not be interpreted for causality. The study has the potential to guide investors in understanding the errors they are making while investing during the pandemic and the ways to deal with them. The study could provide insights to the financial advisors in understanding their customers. The implications of the study may include inputs of the errors committed by them during the pandemic. Despite the fact that an enormous amount of literature exists in the field of investors' sentiment, a scarcity of literature is available that measures the relationship between heuristic biases and the perceived impact of the pandemic. The current study attempts to fill this gap in the literature.
\end{abstract}

Keywords Availability $\cdot$ Anchoring $\cdot$ Representativeness $\cdot$ Overconfidence $\cdot$ Covid-19

Shashank Kathpal

shashankkathpal@gmail.com

Asif Akhtar

asifakh@gmail.com

Asma Zaheer

ameraj@kau.edu.sa

Mohd Naved Khan

m.naved@seu.edu.sa

1 Institute of Business Management, GLA University, Mathura, India

2 Mathura, Uttar Pradesh 281406, India

3 Department of Business Administration, Aligarh Muslim University, Aligarh, India

4 Department of Marketing, Faculty of Economics and Administration, King Abdulaziz University, Jeddah, Kingdom of Saudi Arabia

5 College of Administration and Finance, Saudi Electronic University, Riyadh, Kingdom of Saudi Arabia

\section{Introduction}

The outburst of Covid-19 has severely impaired financial activities around the world. This pandemic gave rise to volatility in business and investment. This volatility in business and economy has caught the attention of many researchers, due to which a considerable amount of research has been conducted to investigate the role of Covid-19 in influencing the pattern of investment and expenditure (Baker et al. 2020a, b; Ramelli and Wagner 2020; Zhang et al. 2020). Literature suggests multidimensional effects of volatility on the different facets of investment. Volatility and unpredictability often lead to the sale of a high volume of stocks (Luo et al. 2020). Volatility in the market often clouds the judgment of the investors. Since traditional finance assumes investors' rationality based upon the efficient market hypothesis, investors' erroneous judgments could be analyzed using behavioral finance (Shiller 2003; Kathpal and Siddiquei 2021). The investors' irrationality due to markets' volatility and inefficiency supports the assumptions of investors' bias in behavioral finance. The basic assumption of behavioral 
finance claims the investors' tendency to diverge from the rational decision-making procedure (Daniel et al. 1998; Yoong and Ferreira 2013). This irrationality could be classified into two broad ways, i.e., heuristic biases and cognitive illusions. Heuristics are the shortcuts of mind used by people to decide volatile and uncertain environments. Irrationality about decision making is based on how the problem is presented to people (Shefrin 2002). This framing of the situation was first explained in prospect theory (Kahneman and Tversky 1979). Investors' inclinations toward psychological biases while making investment decisions (Daniel et al. 1998) and the difficulty of eradicating these psychological biases of investors (Kahneman and Riepe 1998) emphasize the importance of comprehending their role in investmentrelated decisions.

Since the pandemic has bought high volatility and uncertainty in the environment, a study that could explain the possible impact of this uncertainty and volatility on investors' decision making could provide valuable insights into the growing literature of investors' bias. This study analyzes the prevalence of heuristic biases in the Bombay Stock Exchange (BSE) during the pandemic outbreak. The target population is the Indian individual stock investors, nine times greater than mutual funds investors (Ramadorai 2013).

Literature reflects a vast amount of studies focusing on secondary information of investors across the world (Barber and Odean 2000; Dhar and Zhu 2006; Frazzini 2006), including India (Kumar and Goyal 2015); a paucity of research exists that uses primary data to evaluate heuristic bias in India (Kumar and Goyal 2015). This study employs primary data to capture investors' behavioral aspects (Lin 2011; Baker et al. 2019). The study was conducted aiming at the following objectives:

- To investigate the presence of heuristic biases during Covid-19.

- To investigate the relationship between propensity toward Covid-19 and heuristic biases.

The other sections of the study include a literature review that reflects the current theory on different heuristic biases and their relation with Covid-19, followed by the research methodology section, which explains the statistical techniques used in this paper to reach the stated objectives. After this, a section on the data analysis and findings is included, followed by the discussion and conclusion.

\section{Literature review}

The year 2020 astonished and frightened the world with Covid-19. Its outbreak caused a high level of uncertainty in economies around the world. During the pandemic, a change in the spending habits and demand patterns of the people was observed. Most of the industries witnessed a change in the demand patterns. Some industries saw a sharp rise in demand, while others faced a sharp decline (Levy and Galili 2006; Luo et al. 2020; Wang and Young 2020). The propensity of its severity could be compared with terrorist aggression in multiple aspects, as people's behavior pattern changes after every act of terrorism (Goodell 2020).

\section{Covid-19 and investment pattern}

Literature also documented that a change in behavior pattern often leads to a change in investment pattern (Luo et al. 2020; Wang and Young 2020). The change in investment pattern was visible in stock markets during Covid-19. Stock markets across the globe experienced high volatility during the pandemic (Zhang et al. 2020; Kathpal and Siddiquei 2021). A tendency to avoid the risk has been observed during uncertain and volatile situations. People avoid long-term gains and sell the riskier stocks in a shorter period during uncertainty and volatility (Burch et al. 2016; Bu et al. 2020; Luo et al. 2020; Wang and Young 2020). This risk aversion has produced a negative return on investment due to the stocks' short-term sales (Kelley and Tetlock 2016). Multiple agencies such as governments and central banks have taken many policy measures to curb the uncertainty caused by the pandemic to build confidence among investors. Despite the generous efforts of these agencies, the precise impact of Covid-19 could not be established. A variety of research has examined the impact of Covid-19, and their results reflect different outcomes of the pandemic for different demography. The USA's economic recovery is expected to be quicker than the previous economic crisis (Hanspal et al. 2020). Despite the expected fast recovery of the world economies, complete market recovery after Covid-19 could take years (Lee 2020).

\section{Covid-19 and cognitive biases}

Covid-19 has made the financial systems highly unpredictable (Baker et al. 2020a). The unpredictability has caused elevated volatility in the stock market (Altig et al. 2020). This volatility in the stock market has also influenced the investment patterns and investors' rationality (Ortmann et al. 2020). Rationality is a prerequisite to achieving the required level of gain. Traditionally, efficient market hypothesis $(\mathrm{EMH})$ is used to dominate finance literature. $\mathrm{EMH}$ assumes rationality in investors. However, a vast amount of literature suggests that investors do not always make rational decisions while investing (Barnes 1984; Waweru et al. 2008; Shah et al. 2018). The cause of this irrational decision making could be found in behavioral finance (Ritter 2003; Al-Tamimi 2006; Ikram 2016). Behavioral finance is 
the branch of finance that examines an investor's psychological hindrances while making rational decisions (Waweru et al. 2008; Ikram 2016; Khan 2020). These psychological biases can be classified into two categories: first heuristic biases and second mental structures or frame dependence (Waweru et al. 2008; Zindel et al. 2014). Heuristic biases are the rule of thumb used by investors in uncertain and complex situations often resulting in poor decision making (Abarbanell and Bernard 1992; Shah et al. 2018). The heuristic biases include availability bias, overconfidence, representativeness, gambler's fallacy, and anchoring bias (Waweru et al. 2008; Shah et al. 2018). Irrationality in frame dependence occurs due to presenting a problem in a specific structure (Waweru et al. 2008; Shah et al. 2018). One of the well-known examples promoting frame dependence is prospect theory (Kahneman and Tversky 1979). Major biases in frame dependence include loss aversion, disposition effect, mental accounting, and sunk cost fallacy (Pompian and Wood 2006; Shah et al. 2018).

Since Covid-19 has bought high uncertainty in the economic environment (Baker et al. 2020a; Kathpal and Siddiquei 2021), examining the biases that could cloud the investors' rational judgment becomes imperative. This study attempts to examine the relationship between Covid-19 and heuristic biases.

\section{Heuristics' Bias}

For a high level of rationality, a superior level of cognitive and intellectual capabilities is required. It enables people to handle complex problems rationally. To solve such complex problems, people tend to take shortcuts. These mental shortcuts discourage people from making an entirely rational decision (Bazerman 1998; Baron 1998). The phenomenon of taking mental shortcuts for dealing with complex problems is termed heuristics. Investors use heuristics to ease the decision-making process in complex situations (Barnes 1984; Ritter 2003). The heuristics and biases are the prime reason for an adverse outcome (Barnes 1984). These heuristics could influence investment and other finance-related decisions (Debondt and Thaler 1990; Abarbanell and Bernard 1992). This paper examines the four most prominent heuristics biases: availability, anchoring, representation, and overconfidence (Waweru et al. 2008; Shah et al. 2018). These four biases are used to reduce the intensity of risk in uncertain times (Debondt and Thaler 1990; Abarbanell and Bernard 1992). Some of the most prominent studies indicating these biases are:

\section{Overconfidence}

In the overconfidence heuristic, a person has superfluous trust in his/her judgments and abilities (Pompian and Wood
2006). In this bias, people highly value their reasoning and cognitive capabilities (Debondt and Thaler 1995; Hvide 2002). Overconfidence often leads to over-precision of skills and decisions (Statman et al. 2006; Moore and Healy 2008). The people with overconfidence heuristic bias overestimate their abilities and undermine others' abilities (Odean 1998; Larrick et al. 2007; Duttle 2015).

Overconfidence and investment behavior: The Overconfidence heuristic significantly impacts investors' rational decision making (Bakar and Yi 2016). An investor with overconfidence bias often forecasts high profits and ignores its risk (Shefrin 2000; Baker and Nofsinger 2002). Their trading frequency is higher while returns are lower than the average market returns (Barber and Odean 2002; Park et al. 2010; Trinugroho and Sembel 2011). Literature associates overconfidence with poor investment choices (Chen et al. 2007; Park et al. 2010; Bashir et al. 2013; Kengatharan and Kengatharan 2014) and impaired rationality among investors (Debondt 1998; Seppälä 2009; Waweru et al. 2008; Kafayat 2014).

\section{Representativeness}

The cognitive heuristic is where a person takes mental shortcuts based on the stereotypes (Shefrin 2005), i.e., matching the similarity of an event with the extent to which it characterizes the people (Kahneman and Tversky 1979; DeBondt and Thaler 1995). People with representativeness bias give importance to their recent experience over their long-term experience (Ritter 2003). The problem with judgments of people with representativeness bias is similar to the judgment-related problem that arises from stereotyping. Just like stereotyping, the ground knowledge of the situation often remains neglected (Shefrin 2008). This neglect of ground reality could take two forms, i.e., sample size neglect and base rate neglect. In sample size neglect, the decision is taken by generalizing either the little information available or assuming the small illustrations representative of the population (Barberis and Thaler 2003; Pompian and Wood 2006). The rationale behind using representativeness could range from little comprehension of the forecasting concept to overshadowing any particular recent event over the longterm events (Kahneman and Tversky 1979).

Representativeness and investment behavior: Literature suggests a mixed relationship between representativeness and positive investment behavior. An improved decision making and better returns on investment have been documented in some studies due to representativeness (Toma 2015; Irshad et al. 2016; Ikram 2016). Contrary to this, poor decision making and low returns due to representativeness bias in individual investors have also been documented (Chen et al. 2007). The impact of representativeness bias 
could also be seen among institutional investors (Lakonishok et al. 1994; Waweru et al. 2008).

\section{Availability}

The availability heuristic is the mental shortcut where a person tends to rely on the conveniently available information (Ngoc 2014). An event's likelihood is assessed by its ease coming to one's mind (Kahneman and Tversky 1979). Since the importance is given to the recurrence rate of an outcome that comes to mind, the analysis is highly influenced by information availability rather than scientific temperament (Brahmana et al. 2012).

Availability and investment behavior: The relationship between availability and investment behavior remained inconclusive in the existing literature. The literature has reflected a positive relationship between availability heuristics and investment behavior, i.e., an improvement in decision making due to availability bias (Ikram 2016; Khan 2020). In contrast, other studies have indicated a negative effect of availability heuristics on decision making (Massa and Simonov 2005; Waweru et al. 2008).

\section{Anchoring}

This heuristic emphasizes the people's disposition to rely upon initial information (anchor). After establishing the anchor, the decisions taken give excess weight to it (Slovic and Lichtenstein 1971). Kahneman and Tversky (1979) explain anchoring by arguing that similar phenomena also vary if the initial references are different. In conclusion, an anchor could be an irrelevant base for decision making (Pompian and Wood 2006).

Anchoring and investment behavior: A significant relationship is documented between anchoring and investment decision (Waweru et al. 2008; Lowies et al. 2016). The impact of anchoring varies with situations. The situations for decision making could range from judicial decisions (Englich et al. 2006) to job performance (Latham et al. 2008). In riskier decisions, anchoring has positively affected decision making (Ishfaq and Anjum 2015). In a nutshell, anchoring bias significantly impacts investors' decision making (Abraham et al. 2014).

Hypothesis: Hypothesis 1(H1): No relationship exists between the perceived impact of Covid-19 and overconfidence bias.

Hypothesis 2(H2): No relationship exists between the perceived impact of Covid-19 and representativeness bias.

Hypothesis 3(H3): No relationship exists between the perceived impact of Covid-19 and availability bias.

Hypothesis 4(H4): No relationship exists between the perceived impact of Covid-19 and anchoring bias.

\section{Gap analysis}

a. The authors could not find any literature that examines the relationship between Covid-19 and heuristic biases.

b. A limited research exists which examines the investor's bias in developing countries during unprecedented challenges.

c. The existing literature demonstrates some contradictory findings such as: (i) on the relationship between availability biases and decision-making capacity (Massa and Simonov 2005; Waweru et al. 2008; Ikram 2016; Khan 2020); and (ii) on the relationship between availability bias and rational decision making (Chen et al. 2007; Toma 2015; Irshad et al. 2016).

\section{Methodology}

\section{Questionnaire}

A self-administered questionnaire was developed containing demography, Covid-19 perception, and heuristic biases concerning India's individual investors. Academic as well as industry experts reviewed the questionnaire. The questionnaire on Covid-19 was developed with the help of experts. Every construct and item of the study has been identified with extensive literature review and validated by experts from academics (Bohrnstedt 1983; Caro and Garcia 2007). The basis for the questionnaire on heuristic biases was taken from existing literature (Wood and Zaichkowsky 2004; Lin 2011). The questionnaire consists of two sections, where section A deals with respondents' demographic profile and section B focuses on questions related to Covid-19 and heuristic biases using a five-point Likert scale. The details of the items used for each construct are as follows:

a. Overconfidence Bias: To measure the overconfidence bias, a four-item scale was used, which was developed referring to Prosad et al. (2015).

b. Representative Bias: This bias was measured using four items. The first two items were taken from Waweru et al. (2008), whereas the last two items were taken from Sarwar et al. (2014).

c. Availability Bias: To measure this bias, we used four items. The first two items were taken from Luong and Thi Thu Ha (2011), whereas the last two items were taken from Kudryavtsev et al. (2013).

d. Anchoring Bias: This bias was measured using five items. The first two items were taken from Baker et al. (2019), the third item is taken from Pandey and Jessica 
(2019), and the last two items were taken from Waweru et al. (2008).

e. Covid-19: A four-item scale was used to measure the perceived impact of Covid-19, which was developed referring to Kathpal and Siddiquei (2021).

\section{Sample}

\section{Area of sample}

This study's target population was the individual investors of the Bombay Stock Exchange (BSE). The sample area from which the data are collected is Delhi-NCR. Investors' details were taken from some of the brokerage firms of Delhi-NCR. The rationale behind selecting Delhi region is due to its highest per capita income in the country, which is approximately three times the average per capita income of India (Nanda 2021). More than half of the trading amount of India happens in Delhi (Prosad et al. 2015), making it a big prospect for stock market investment. Sample size.

An adequate sample size is necessary for the data adequacy to control systematic variance (Hoogland and Boomsma 1998), but a large sample size does not need to categorically remove systematic variance (Worthington and Whittaker 2006). To ensure sampling adequacy, this studied determined the sample size using four criteria:

i. Using Rule of Thumbs: Many rule of thumb exists to determine the sample size. One of which states that any sample size greater than 200 is sufficient (Boomsma and Hoogland 2001; Hoe 2008; Singh et al. 2016). Another important thumb rule to determine sample size is the equation " $5 \mathrm{w} \leq \mathrm{n} \leq 15 \mathrm{w}$ " (here, the $\mathrm{w}$ reflects the number of items taken in the survey, and $\mathrm{n}$ represents the ideal amount of responses). Since the number of items used in the instrument was 21 , the ideal amount should lie between 105 and 315 .

ii. Using the number of items/indicators: Another rule state that has a sample size 10 times the items makes the data significant (Nunnally and Bernstein 1967; Wang and Wang 2019).

iii. Using Factor Loading: The ideal sample size is inversely proportional to the value of factor loading. If the factor loading value is 0.5 and 0.8 , the sample size should be 460 and 120, respectively (Wolf et al. 2013; Kyriazos 2018). Since the minimum factor loading for each item of the sample is 0.73 , a sample size of more than 250 is adequate for the study.

iv. Verification from existing literature: We examined the sample size used in the literature which measures the investors' bias using a self-administered questionnaire and found that a sample size of more than 200 respondents is sufficient to perform the analysis
(Jhandir and Elahi 2014; Kansal and Singh 2015; Chhapra et al. 2018; Rasheed et al. 2018; Ahmad 2020).

\section{Sampling technique}

Investors were contacted via phone or personal visits from June 2020 to November 2020. A total of 500 investors were contacted to fill the questionnaire. Out of the 500,340 people filled the questionnaire, out of which 50 were found incomplete. Hence, 290 answers were considered for the investigation.

\section{Data analysis}

The data collected was analyzed using SPSS 21 and AMOS 18. Since the data are cross-sectional in nature, we used structural equation modeling (SEM) to perform path analysis and confirmatory factor analysis (CFA) to examine the relationship between the given constructs (Hox and Bechger 1998).

\section{Results}

\section{Demography}

The demography of the 290 respondents is presented in Table 1. This sample consists of $73 \%$ males, indicating the high participation of male investors in BSE. This gender disparity could be explained by Central Depository Services Ltd (CSDL), stating that $75 \%$ of Indian investors are male. The existing literature on stock exchanges of India reflects similar figures in their research (Kalra Sahi and Pratap Arora 2012; Jhandir and Elahi 2014; Akhtar and Das 2019; Ahmad 2020). More than $85 \%$ of investors are graduates, out of which $55 \%$ of the population are postgraduates, which reflects that the investors are majorly educated. Less than $33 \%$ of investors are either self-employed or working in the private sector. The results also reflect that majority of the investors earn at least 10,00,000/-rupees per annum.

\section{Common method bias (CMB)}

For studies using cross-sectional data, the possibility of CMB might arise. This CMB could significantly affect the results (Podsakoff and Organ 1986). Since the current study employs cross-sectional data, the variance in eigenvalue was calculated using principal component analysis. Table 2 reflects $37.876 \%$ of the first-factor variance, which is considerably less than $50 \%$. Hence, we can conclude that CMB does not influence the results. 
Table 1 Demography

\begin{tabular}{|c|c|c|}
\hline Description & $\begin{array}{l}\text { Frequency (in } \\
\text { numbers) }\end{array}$ & $\begin{array}{l}\text { Frequency (in } \\
\text { percentage) }\end{array}$ \\
\hline \multicolumn{3}{|l|}{ Gender } \\
\hline Male & 212 & 73.10 \\
\hline Female & 78 & 26.90 \\
\hline \multicolumn{3}{|l|}{ Education } \\
\hline Up to graduation & 38 & 13.10 \\
\hline Graduate & 89 & 30.69 \\
\hline Postgraduate & 107 & 36.90 \\
\hline Doctorate & 56 & 19.31 \\
\hline \multicolumn{3}{|l|}{ Occupation } \\
\hline Private employment & 38 & 13.10 \\
\hline Government employment & 89 & 30.69 \\
\hline Self-employed & 56 & 19.31 \\
\hline Others & 107 & 36.90 \\
\hline \multicolumn{3}{|l|}{ Experience of investment } \\
\hline Less than 1 year & 51 & 17.59 \\
\hline Between 1 and 5 years & 63 & 21.72 \\
\hline Between 5 and 9 years & 102 & 35.17 \\
\hline More than 9 years & 74 & 25.52 \\
\hline \multicolumn{3}{|l|}{ Yearly income (in Rs.) } \\
\hline Less than $3,00,000$ & 49 & 16.90 \\
\hline $3,00,000-6,00,000$ & 58 & 20.00 \\
\hline $6,00,000-10,00,000$ & 69 & 23.79 \\
\hline More than $10,00,000$ & 114 & 39.31 \\
\hline
\end{tabular}

\section{Reliability}

The method employed to test reliability is Cronbach's alpha. It analyzes the reliability of any given scale. A value above 0.7 represents the excellent acceptability of the scale (Sekaran 2000). Table 3 reflects the excellent reliability of the items. Multicollinearity.

Multicollinearity refers to the linear relationship between variables. It could hamper the regression values and make the predictions difficult. If the correlation between the variables is lower than 0.8 , it considerably diminishes multicollinearity concerns (Tabachnick and Fidell 2007). Table 4 signifies that the level of multicollinearity is an acceptable range, as all of the variables have a correlation value of less than 0.8

\section{Exploratory factor analysis (EFA)}

The technique of factor analysis is used to investigate the items' structure and validation of a scale. The principal component analysis is employed to perform factor analysis. After analyzing multicollinearity, the next step is to give structure to the measured items using EFA. EFA is dependent on the results of the Kaiser-Meyer-Olkin test. Table 5 reveals the value of $\mathrm{KMO}$ as 0.913 , which satisfies the assumptions of EFA (Norman 2010). The acceptable value of factor loading in EFA should be greater than 0.63 (Comrey and Lee 1992). Table 6 reflects that factor loading of all the given items is greater than 0.73 , indicating a robust relationship between factors and variables.

\section{Measurement model}

Multiple indicators were analyzed to examine the goodness of fit for the proposed framework, including $X^{2} / d f$, RMSEA, TLI, CFI, RFI, IFI, and NFI (Hair et al. 1995; Schumacker and Lomax 1996; Byrne 2001). Table 7 demonstrates the suitable value of indicators and their actual value obtained from the analysis. All of the given indicators reveal a good fit for the proposed model (Fig. 1).

\section{Structural model}

In order to analyze the coefficients of the proposed structure, a maximum likelihood procedure is employed. Table 8 represents the estimations of the proposed model. If the $p$ value $<0.05$ and C.R. $>1.96$, the estimates are considered significant. Apart from estimating regression between Covid-19 and overconfidence, all other heuristic biases significantly correlate with Covid-19.

\section{Hypothesis testing}

The null hypothesis is rejected in the relationship between Covid-19 and overconfidence bias, whereas it is accepted for all other heuristic biases (Table 9).

\section{Conclusion and discussions}

The paper aims at examining the existence of heuristic biases in Indian investors. It further explores the relationship between the perceived effects of Covid-19 and different heuristic biases. The study employs primary data collected through a self-administered questionnaire. The results indicate that a large section of Indian investors belongs to the upper-class segment as their income is more than $10,00,000 /$ - rupees per annum. This finding supports the results of Baker et al. (2019). The findings suggest that investors have used mental shortcuts during the current pandemic for investment-related decisions to handle the uncertainty. This is due to the high influence of representative bias during the pandemic. The use of heuristics during uncertainty is in line with the existing literature (Bloom et al. 2007; Waweru et al. 2008; Shah et al. 2018). The study provides evidence for enhanced anchoring and availability bias during Covid-19. We could comfortably infer that people make 
Table 2 Total variance

\begin{tabular}{|c|c|c|c|c|c|c|}
\hline \multirow[t]{2}{*}{ Factor } & \multicolumn{3}{|c|}{ Eigenvalues } & \multicolumn{3}{|c|}{ Extraction sums of squared loadings } \\
\hline & Total & Variance $(\%)$ & Cumulative (\%) & Total & Variance $(\%)$ & Cumulative (\%) \\
\hline 1 & 8.496 & 40.458 & 40.458 & 7.954 & 37.876 & 37.876 \\
\hline 2 & 3.301 & 15.717 & 56.175 & & & \\
\hline 3 & 2.221 & 10.576 & 66.751 & & & \\
\hline 4 & 2.069 & 9.852 & 76.603 & & & \\
\hline 5 & 1.070 & 5.096 & 81.700 & & & \\
\hline 6 & .415 & 1.976 & 83.676 & & & \\
\hline 7 & .376 & 1.792 & 85.467 & & & \\
\hline 8 & .349 & 1.663 & 87.130 & & & \\
\hline 9 & .313 & 1.493 & 88.622 & & & \\
\hline 10 & .277 & 1.320 & 89.943 & & & \\
\hline 11 & .271 & 1.292 & 91.234 & & & \\
\hline 12 & .266 & 1.266 & 92.500 & & & \\
\hline 13 & .240 & 1.143 & 93.643 & & & \\
\hline 14 & .214 & 1.019 & 94.662 & & & \\
\hline 15 & .201 & .958 & 95.620 & & & \\
\hline 16 & .188 & .897 & 96.517 & & & \\
\hline 17 & .178 & .846 & 97.363 & & & \\
\hline 18 & .165 & .786 & 98.149 & & & \\
\hline 19 & .144 & .687 & 98.836 & & & \\
\hline 20 & .135 & .642 & 99.478 & & & \\
\hline 21 & .110 & .522 & 100.000 & & & \\
\hline
\end{tabular}

Extraction method: principal axis factoring

Table 3 Reliability statistics

\begin{tabular}{lll}
\hline Variable & Cronbach's alpha & No. of items \\
\hline Availability & 0.924 & 4 \\
Anchoring & 0.921 & 5 \\
Representativeness & 0.915 & 4 \\
Overconfidence & 0.931 & 4 \\
Covid-19 & 0.855 & 4 \\
\hline
\end{tabular}

their investment decisions based on the available information only, more specifically based on a particular reference point. The enhancement of the sentiments for investment and reduction in rational decision making during Covid-19 is in line with the findings of Sun et al. (2021). This study explains that barring overconfident investors, Covid-19 has influenced other types of investors in India to take different mental shortcuts while making an investment decision during an uncertain environment. The findings might not be generalized for every uncertain situation, as the Covid-19 is an event that has not occurred before (Caggiano et al. 2020). This high uncertainty and fear would have led to a high level of bias among the investors (Hoang and Syed 2021).

The current study is the first study that reflects the impact of Covid-19 on heuristic biases, and it also adds valuable insights to the plethora of literature on investors' decision
Table 4 Correlation between variables

\begin{tabular}{llllll}
\hline & OverCon & Anchor & Represent & Covid & Available \\
\hline OverCon & & & & & \\
Correlation & 1 & $.191^{* *}$ & $.157^{* *}$ & .081 & $.239^{* *}$ \\
Significance & & .001 & .008 & .169 & .000 \\
$\mathrm{~N}$ & 289 & 289 & 289 & 289 & 289 \\
Anchor & & & & & \\
Correlation & $.191^{* *}$ & 1 & $.607 * *$ & $.405^{* *}$ & $.403^{* *}$ \\
Significance & .001 & & .000 & .000 & .000 \\
N & 289 & 289 & 289 & 289 & 289 \\
Represent & & & & & \\
Correlation & $.157 * *$ & $.607 * *$ & 1 & $.607 * *$ & $.370^{* *}$ \\
Significance & .008 & .000 & & .000 & .000 \\
N & 289 & 289 & 289 & 289 & 289 \\
Covid & & & & & \\
Correlation & .081 & $.405 * *$ & $.607 * *$ & 1 & $.353^{* *}$ \\
Significance & .169 & .000 & .000 & & .000 \\
N & 289 & 289 & 289 & 289 & 289 \\
Available & & & & $.353^{* *}$ & 1 \\
Correlation & $.239 * *$ & $.403^{* *}$ & $.370^{* *}$ & .359 \\
Significance & .000 & .000 & .000 & .000 & \\
N & 289 & 289 & 289 & 289 & 289 \\
\hline
\end{tabular}

*** Correlation is significant at the 0.01 level (2-tailed) 
Table 5 Bartlett's and KMO test
Kaiser-Meyer-Olkin and Bartlett's test

The measure of sampling adequacy (Kaiser-Meyer-Olkin)

Test of sphericity (Bartlett's)
913

Chi-square

5316.815

Degrees of freedom

210

Significance
Table 6 Rotated component matrix

\begin{tabular}{|c|c|c|c|c|c|}
\hline & Comp & & & & \\
\hline & 1 & 2 & 3 & 4 & 5 \\
\hline Anchor1 & .866 & & & & \\
\hline Anchor3 & .861 & & & & \\
\hline Anchor2 & .851 & & & & \\
\hline Anchor4 & .836 & & & & \\
\hline Anchor5 & .824 & & & & \\
\hline OverC3 & & .921 & & & \\
\hline OverC4 & & .917 & & & \\
\hline OverC2 & & .914 & & & \\
\hline OverC1 & & .884 & & & \\
\hline Availab2 & & & .912 & & \\
\hline Availab3 & & & .858 & & \\
\hline Availab1 & & & .852 & & \\
\hline Availab4 & & & .835 & & \\
\hline Covid3 & & & & .851 & \\
\hline Covid2 & & & & .829 & \\
\hline Covid4 & & & & .814 & \\
\hline Covid1 & & & & .739 & \\
\hline Repres1 & & & & & .831 \\
\hline Repres3 & & & & & .799 \\
\hline Repres4 & & & & & .770 \\
\hline Repres2 & & & & & .768 \\
\hline
\end{tabular}

Extraction method: PCA

Rotation method: Varimax

Table 7 Goodness of fit

\begin{tabular}{llc}
\hline Measures of absolute fit & Acceptable & Result \\
\hline $\begin{array}{l}\text { Parsimonious tests } \\
\begin{array}{l}\text { Chi-square/degrees of freedom } \\
\left(\chi^{2} / d f\right)\end{array}\end{array}$ & $1-5$ & 2.048 \\
RMSEA & Less than 0.08 & 0.06 \\
$\begin{array}{l}\text { Incremental fit tests } \\
\text { NFI }\end{array}$ & More than 0.85 & 0.931 \\
RFI & More than 0.85 & 0.913 \\
CFI & More than 0.85 & 0.963 \\
TLI & More than 0.85 & 0.954 \\
IFI & More than 0.85 & 0.963 \\
\hline
\end{tabular}

$\mathrm{Hu}$ and Benter (1999) making under uncertainty. However, its findings cannot be generalized for two reasons; one, because we are still in the pandemic, and the behavior of investors after one year of the beginning of the pandemic needs to be examined. Therefore, we encourage the academicians to investigate the influence of heuristics after one year of Covid-19. We also encourage academicians to examine the level of heuristic biases among investors in the post-Covid-19 era. The second shortcoming of our study is the sampling area which is limited to Delhi. We encourage the authors to conduct a similar pan India study to confirm the generalization of the results.

\section{Implications}

The current study aspires to contribute to the growing literature on behavioral finance by providing insights into the heuristic biases of Indian investors. This study also attempts to extend the current literature of investors' bias by adding the influence of the pandemic on heuristics biases. The study's most important finding indicates amplification in the investors' tendency to take mental shortcuts when faced with an unprecedented situation like Covid-19. The findings are helpful for both academicians and investors. From an academic point of view, it could provide insights on investor behavior during the pandemic, especially for those interested in exploring the field of investors' bias. The study explains how the perception of Covid-19 influences investors in making errors in judgment by adopting mental shortcuts. If an academician found that investors are using mental shortcuts, they could explore any uncertainty in the market, causing this heuristic bias. The study's findings suggest that people often make quick judgments in representativeness, availability, and anchoring bias during uncertainty. Therefore, the investment advisors and consultants will find it more convenient to convince their clients, especially during volatile situations. Since the results indicate no significant effect of the pandemic on the overconfident investors, it could be inferred that even an uncertain situation like Covid-19 does not affect the investment strategy of overconfident people. This insight is beneficial for academicians exploring the behavior of overconfident investors. The study could also be proven helpful for the investment advisors 


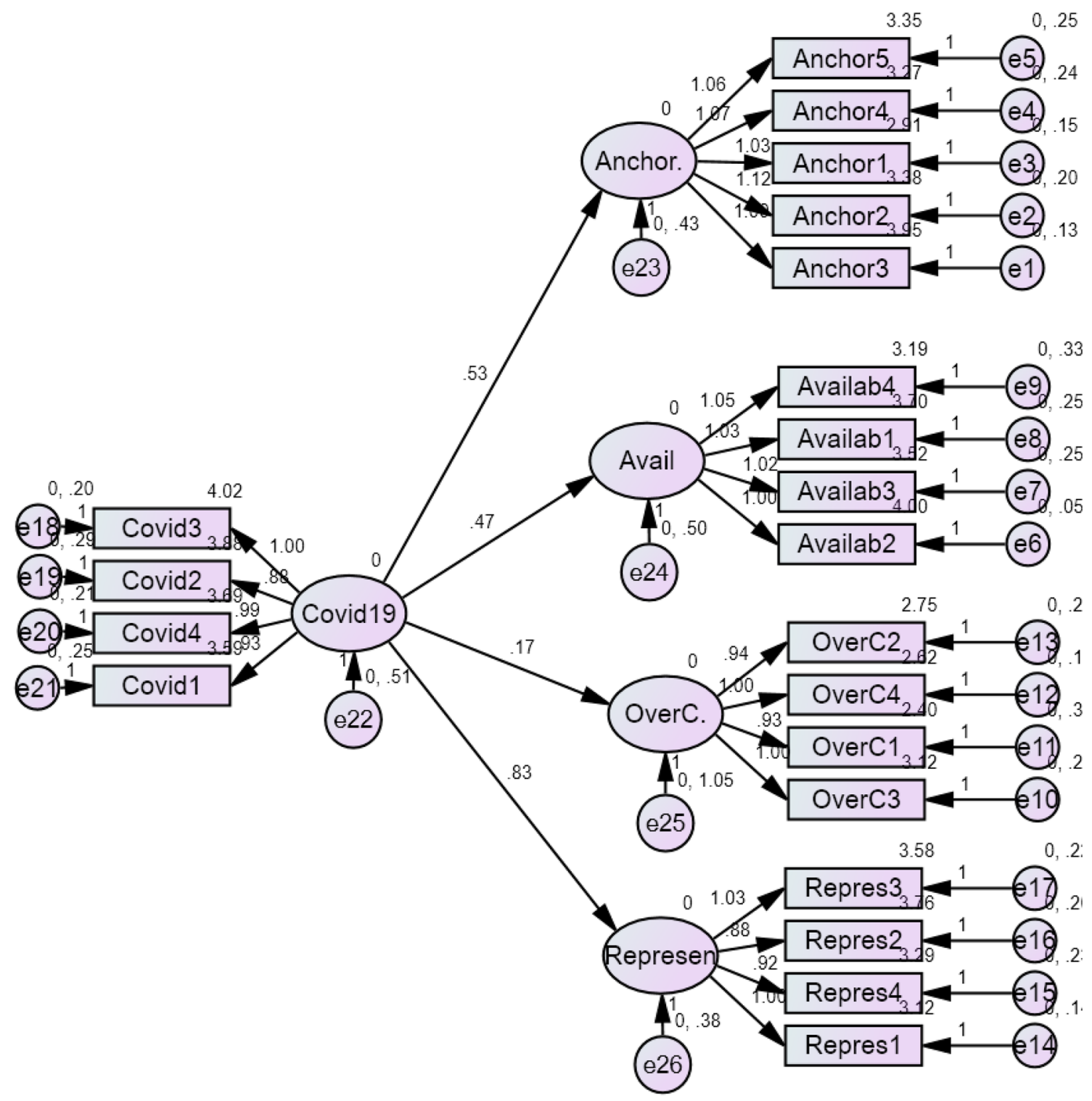

Fig. 1 Structural equation of proposed model

Table 8 Relationship between Covid-19 and heuristic biases

\begin{tabular}{lllllll}
\hline & & & $\begin{array}{l}\text { Regression weight } \\
\text { estimation }\end{array}$ & S.E & C.R & $P$ \\
\hline Anchoring & $<-$ & Covid19 & 0.532 & 0.064 & 8.281 & 0.000 \\
Availability & $<-$ & Covid19 & 0.473 & 0.066 & 7.14 & 0.000 \\
Overconfidence & $<-$ & Covid19 & 0.172 & 0.092 & 1.866 & 0.062 \\
Representativeness & $<-$ & Covid19 & 0.833 & 0.069 & 12.055 & 0.000 \\
\hline
\end{tabular}

in educating the individual investors about the possible errors they could commit due to market volatility. The study could also be proven beneficial to regulatory bodies by providing insights into psychological biases influencing investors during the pandemic. 
Table 9 Verification of hypothesis

\begin{tabular}{lll}
\hline Hypothesis & Outcome & Relationship \\
\hline H1: No relationship exists between the perceived impact of Covid-19 and overconfidence & Supported & No significant relation \\
H2: No relationship exists between the perceived impact of Covid-19 and representativeness bias & Not supported & Positive and significant \\
H3: The no relationship exists between the perceived impact of Covid-19 and availability bias & Not supported & Positive and significant \\
H4: No relationship exists between the perceived impact of Covid-19 and anchoring & Not supported & Positive and significant \\
\hline
\end{tabular}

\section{References}

Abarbanell, J.S., and V.L. Bernard. 1992. Tests of analysts' overreaction/underreaction to earnings information as an explanation for anomalous stock price behavior. The Journal of Finance 47(3): 1181-1207.

Abraham, E., S. Colin, and A. Valentini. 2014. Long-time relaxation in pilot-wave theory. Journal of Physics A: Mathematical and Theoretical 47(39): 395306.

Ahmad, M. 2020. Does underconfidence matter in short-term and long-term investment decisions? Evidence from an emerging market. Management Decision. https://doi.org/10.1108/ MD-07-2019-0972.

Akhtar, F., and N. Das. 2019. Predictors of investment intention in Indian stock markets: Extending the theory of planned behavior. International Journal of Bank Marketing 37(1): 97-119. https:// doi.org/10.1108/IJBM-08-2017-0167.

Al-Tamimi, H.A.H. 2006. Factors influencing individual investor behavior: An empirical study of the UAE financial markets. The Business Review 5(2): 225-233.

Altig, D., S. Baker, J.M. Barrero, N. Bloom, P. Bunn, S. Chen, et al. 2020. Economic uncertainty before and during the COVID-19 pandemic. Journal of Public Economics 191: 104274.

Bakar, S., and A.N.C. Yi. 2016. The impact of psychological factors on investors' decision making in Malaysian stock market: A case of Klang Valley and Pahang. Procedia Economics and Finance 35: 319-328.

Baker, H.K., and J.R. Nofsinger. 2002. Psychological biases of investors. Financial Services Review 11(2): 97.

Baker, H.K., S. Kumar, and N. Goyal. 2019. Personality traits and investor sentiment. Review of Behavioral Finance. https://doi. org/10.1108/RBF-08-2017-0077.

Baker, S.R., R.A. Farrokhnia, S. Meyer, M. Pagel, and C. Yannelis. 2020a. How does household spending respond to an epidemic? Consumption during the 2020 COVID-19 pandemic. The Review of Asset Pricing Studies 10(4): 834-862.

Baker, S.R., N. Bloom, S.J. Davis, K. Kost, M. Sammon, and T. Viratyosin. 2020b. The unprecedented stock market reaction to COVID-19. The Review of Asset Pricing Studies 10(4): 742-758.

Barber, B.M., and T. Odean. 2002. Does online Trading change investor behavior? European Business Organization Law Review 3(1): 83-128.

Barber, B.M., and T. Odean. 2000. Investors, trading is hazardous to your wealth: The common stock investment performance of individual. The Journal of Finance 55(2): 773-806.

Barberis, N., and R. Thaler. 2003. Behavioral finance. George M. Constan.

Barnes, J.H., Jr. 1984. Cognitive biases and their impact on strategic planning. Strategic Management Journal 5(2): 129-137.

Baron, R.A. 1998. Cognitive mechanisms in entrepreneurship: Why and when entrepreneurs think differently than other people. Journal of Business Venturing 13(4): 275-294.

Bashir, T., N. Azam, A. A. Butt, A. Javed, and A. Tanvir. 2013. Are behavioral biases influenced by demographic characteristics \& personality traits? Evidence from Pakistan. European Scientific Journal 9(29).

Bazerman, C. 1998. Emerging perspectives on the many dimensions of scientific discourse. In: Reading science: Critical and functional perspectives on discourses of science, 15-28.

Bloom, N., S. Bond, and J. Van Reenen. 2007. Uncertainty and investment dynamics. The Review of Economic Studies 74(2): 391-415.

Bohrnstedt, G. 1983. Measurement. In A hand-book of survey research, ed. P. Rossi, J. Wright, and A. Anderson. San Diego, CA: Academy Press.

Boomsma, A., and J.J. Hoogland. 2001. The robustness of LISREL modeling revisited. Structural equation models: Present and future. A Festschrift in honor of Karl Jöreskog 2(3): 139-168.

Brahmana, R. K., C. W. Hooy, and Z. Ahmad. 2012. Psychological factors on irrational financial decision making. Humanomics.

Bu, D., T. Hanspal, Y. Liao, and Y. Liu. 2020. Risk-taking during a global crisis: Evidence from Wuhan. Covid Economics 5: 106-146.

Burch, Timothy R., Douglas R. Emery, and Michael E. Fuerst. 2016. Who moves markets in a sudden market-wide crisis? evidence from 9/11. Journal of Financial and Quantitative Analysis 51: 463-487.

Byrne, B. 2001. Structural equation modelling with AMOS. New Jersey: Lawrence Erlbaum Associate.

Caggiano, G., E. Castelnuovo, and R. Kima. 2020. The global effects of Covid-19-induced uncertainty. Economics Letters 194: 109392.

Caro, L.M., and J.A.M. Garcia. 2007. Measuring perceived service quality in urgent transport service. Journal of Retailing and Consumer Services 14(1): 60-72.

Chen, G., K.A. Kim, J.R. Nofsinger, and O.M. Rui. 2007. Trading performance, disposition effect, overconfidence, representativeness bias, and experience of emerging market investors. Journal of Behavioral Decision Making 20(4): 425-451.

Chhapra, I.U., M. Kashif, R. Rehan, A. Bai, S. Zulfikar, and A. Bhutto. 2018. An empirical investigation of investor's behavioral biases on financial decision making. Asian Journal of Empirical Research 8(3): 99-109. https://doi.org/10.18488/journal.1007/ 2018.7.3/1007.3.99.109.

Comrey, A. L. and H. B. Lee. 1992. A first course in factor analysis (2nd edn). Hillsdale.

Daniel, K., D. Hirshleifer, and A. Subrahmanyam. 1998. Investor psychology and security market under-and overreactions. The Journal of Finance 53(6): 1839-1885.

De Bondt, W.F. 1998. A portrait of the individual investor. European Economic Review 42(3-5): 831-844.

De Bondt, W. F. and R. H. Thaler. 1990. Do security analysts overreact?. The American Economic Review, 52-57.

De Bondt, W.F., and R.H. Thaler. 1995. Financial decision-making in markets and firms: A behavioral perspective. Handbooks in Operations Research and Management Science 9: 385-410.

Dhar, R., and N. Zhu. 2006. Up close and personal: Investor sophistication and the disposition effect. Management Science 52(5): 726-740. 
Duttle, K. 2015. Disentangling two causes of biased probability judgment-cognitive skills and perception of randomness. Ruhr Economic Paper, 568.

Englich, B., T. Mussweiler, and F. Strack. 2006. Playing dice with criminal sentences: The influence of irrelevant anchors on experts' judicial decision making. Personality and Social Psychology Bulletin 32(2): 188-200.

Frazzini, A. 2006. The disposition effect and underreaction to news. The Journal of Finance 61(4): 2017-2046.

Goodell, John W. 2020. Covid-19 and finance: Agendas for future research. Finance Research Letters 35: 101512.

Hair, J., R. Anderson, R. Tatham, and W. Black. 1995. Multivariate data analysis with readings. Englewood Cliffs: Prentice-Hall International.

Hanspal, Tobin, Annika Weber, and Johannes Wohlfart. 2020. Income and wealth shocks and expectations during the covid-19 pandemic. In: Working paper 13/20. University of Copenhagen.

Van Hoang, T.H., and Q.R. Syed. 2021. Investor sentiment and volatility prediction of currencies and commodities during the COVID19 pandemic. Asian Economics Letters 1(4): 18642.

Hoe, S.L. 2008. Issues and procedures in adopting structural equation modelling technique. Journal of Quantitative Methods 3(1): 76.

Hoogland, J.J., and A. Boomsma. 1998. Robustness studies in covariance structure modeling: An overview and a meta-analysis. Sociological Methods and Research 26: 329-367. https://doi.org/10. 1177/0049124198026003003.

Hox, J.J., and T.M. Bechger. 1998. An introduction to structural equation modelling. Family Science Review 11: 354-373.

Hvide, H.K. 2002. Tournament rewards and risk-taking. Journal of Labor Economics 20(4): 877-898.

Ikram, Z. 2016. An empirical investigation on behavioral determination, impact on investment decision making, moderating role of locus of control. Journal of Poverty, Investment and Development 26.

Irshad, S., W. Badshah, and U. Hakam. 2016. Effect of representativeness bias on investment decision making. Management and Administrative Sciences Review 5(1): 26-30.

Ishfaq, M., and N. Anjum. 2015. Effect of anchoring bias on risky investment decision. Evidence from Pakistan equity market. International Journal of Engineering and Management Research (IJEMR) 5(4): 32-38.

Jhandir, S. U., and M. A. Elahi (2014). Behavioral biases in investment decision making and moderating role of investor's type. In: National Research Conference, 1-24.

Kafayat, A. 2014. Interrelationship of biases: effect investment decisions ultimately. Theoretical and Applied Economics 21(6): $85-110$

Kahneman, D., and A. Tversky. 1979. Prospect theory: an analysis of decision under risk. Econometrica Journal of the Econometric Society 47(2): 263-291.

Kahneman, D., and M.W. Riepe. 1998. Aspects of investor psychology. Journal of Portfolio Management 24(4): 52-65.

Kalra Sahi, S., and A. Pratap Arora. 2012. Individual investor biases: A segmentation analysis. Qualitative Research in Financial Markets 4(1): 6-25. https://doi.org/10.1108/17554171211213522.

Kansal, P. and D. S. Singh. 2015. Investment behavior of engineers: an empirical study. Researchers World Journal of Arts Science and Commerce, July 2016, 20-27. https://doi.org/10.18843/rwjasc/ v6i4/03.

Kathpal, S., and M.I. Siddiquei. 2021. Investigating the impact of covid-19 on investor's bias: An empirical study. Finance India 35(1): 187-204.

Kelley, Eric K., and Paul C. Tetlock. 2016. Retail short selling and stock prices. The Review of Financial Studies 30: 801-834.

Kengatharan, L., and N. Kengatharan. 2014. The influence of behavioral factors in making investment decisions and performance:
Study on investors of Colombo Stock exchange, Sri Lanka. Asian Journal of Finance and Accounting 6(1): 1.

Khan, D. 2020. Cognitive driven biases, investment decision making: The moderating role of financial literacy. SSRN Electronic Journal. https://doi.org/10.2139/ssrn.3514086.

Kudryavtsev, A., G. Cohen, and S. Hon-Snir. 2013. "Rational" or "Intuitive": Are behavioral biases correlated across stock market investors? Contemporary Economics 7(2): 31-53.

Kumar, S., and N. Goyal. 2015. Behavioural biases in investment decision making-A systematic literature review. Qualitative Research in Financial Markets 7: 88-108.

Kyriazos, T.A. 2018. Applied psychometrics: Sample size and sample power considerations in factor analysis (EFA, CFA) and SEM in general. Psychology 9(08): 2207.

Lakonishok, J., A. Shleifer, and R.W. Vishny. 1994. Contrarian investment, extrapolation, and risk. The Journal of Finance 49(5): $1541-1578$.

Larrick, R.P., K.A. Burson, and J.B. Soll. 2007. Social comparison and confidence: When thinking you're better than average predicts overconfidence (and when it does not). Organizational Behavior and Human Decision Processes 102(1): 76-94.

Latham, G.P., L. Borgogni, and L. Petitta. 2008. Goal setting and performance management in the public sector. International Public Management Journal 11(4): 385-403.

Le Luong, P. and D. Thi Thu Ha 2011. Behavioral factors influencing individual investors' decision-making and performance: A survey at the Ho Chi Minh Stock Exchange.

Lee, Don. 2020. Coronavirus recession now expected to be deeper and longer. In: Los Angeles Times 04/01/2020.

Levy, Ori, and Itai Galili. 2006. Terror and trade of individual investors. The Journal of Socio-Economics 35: 980-991.

Lin, H. 2011. Elucidating rational investment decisions and behavioral biases: Evidence from the Taiwanese stock market. African Journal of Business Management 5(5): 1630-1641. https://doi. org/10.5897/AJBM10.474.

Lowies, G. A., J. H. Hall, and C. E. Cloete. 2016. Heuristic-driven bias in property investment decision-making in South Africa. Journal of Property Investment and Finance.

Luo, Yue, Yangyang Chen, and Ji-Chai Lin. 2020. Do terrorist attacks make inventors more risk-taking?. In: Working Paper.

Massa, M., and A. Simonov. 2005. Behavioral biases and investment. Review of Finance 9(4): 483-507.

Moore, D.A., and P.J. Healy. 2008. The trouble with overconfidence. Psychological review 115(2): 502.

Nanda, R. 2021, March 31. Despite Covid-19, Delhi maintains per capita income at three times higher than national average. CNNIBN. https://www.news18.com/news/business/despite-covid-19delhi-maintains-per-capita-income-at-three-times-higher-thannational-average-3512033.html

Ngoc, L.T.B. 2014. Behavior pattern of individual investors in stock market. International Journal of Business and Management 9(1): 1.

Norman, G. 2010. Likert scales, levels of measurement and the "laws" of statistics. Advances in health sciences education 15(5): $625-632$.

Nunnally, J., I. Bernstein, and J.T. Berge. 1967. Psychometric theory (vol. 226): JSTOR.

Odean, T. 1998. Are investors reluctant to realize their losses? The Journal of Finance 53(5): 1775-1798.

Ortmann, R., M. Pelster, and S.T. Wengerek. 2020. COVID-19 and investor behavior. Finance Research Letters 37: 101717.

Pandey, R., and V.M. Jessica. 2019. Sub-optimal behavioural biases and decision theory in real estate: The role of investment satisfaction and evolutionary psychology. International Journal of Housing Markets and Analysis 12(2): 330-348. 
Park, J., P. Konana, B. Gu, A. Kumar, and R. Raghunathan. 2010. Confirmation bias, overconfidence, and investment performance: Evidence from stock message boards. In: McCombs research paper series no. IROM-07-10.

Podsakoff, P.M., and D.W. Organ. 1986. Self-reports in organizational research: Problems and prospects. Journal of Management 12: 531-544.

Pompian, M. M. and A. S. Wood. 2006. Behavioral finance and wealth management: How to build optimal portfolios for private clients.

Prosad, J.M., S. Kapoor, and J. Sengupta. 2015. Behavioral biases of Indian investors: A survey of Delhi-NCR region. Qualitative Research in Financial Markets 7(3): 230-263.

Ramadorai, T. 2013. Capacity constraints, investor information, and hedge fund returns. Journal of Financial Economics 107(2): 401-416.

Ramelli, Stefano and Alexander F. Wagner. 2020. Feverish stock price reactions to covid-19. In: Working paper 20-12, University of Zurich.

Rasheed, M.H., A. Rafique, T. Zahid, and M.W. Akhtar. 2018. Factors influencing investor's decision making in Pakistan: Moderating the role of locus of control. Review of Behavioral Finance 10(1): 70-87. https://doi.org/10.1108/RBF-05-2016-0028.

Ritter, J.R. 2003. Behavioral finance. Pacific-Basin Finance Journal 11(4): 429-437.

Sarwar, A., Z. Mansoor, and N.S. Butt. 2014. Investor's behavior in Pakistan mercantile exchange (PMEX). Science International 26(3): 1371-1377.

Schumacker, R. and R. Lomax. 1996. A beginner guide to structural equation.

Sekaran U. 2000. Measurement: Scaling, reliability, validity research methods for business, vol. 3, pp. 196-218.

Seppälä, A. 2009. Behavioral biases of investment advisors-The effect of overconfidence and hindsight bias.

Shah, S.Z.A., M. Ahmad, and F. Mahmood. 2018. Heuristic biases in investment decision-making and perceived market efficiency. Qualitative Research in Financial Markets 10: 85-110.

Shefrin, E. 2005. Le Noir et le Blanc": Hybrid Myths in Devil in a" Blue Dress" and" LA Confidential. Literature/film Quarterly 33(3): 172-181.

Shefrin, H. 2000. Recent developments in behavioral finance. The Journal of Wealth Management 3(1): 25-37.

Shefrin, H. 2002. Beyond greed and fear: understanding behavioral finance and the psychology of investing. Oxford: Oxford University Press on Demand.

Shefrin, H. 2008. Ending the management illusion: How to drive business results using the principles of behavioral finance. New York: McGraw-Hill.

Shiller, R.J. 2003. From efficient markets theory to behavioral finance. Journal of Economic Perspectives 17(1): 83-104.

Singh, K., M. Junnarkar, and J. Kaur. 2016. Development and Validation. Berlin: Springer.

Slovic, P., and S. Lichtenstein. 1971. Comparison of Bayesian and regression approaches to the study of information processing in judgment. Organizational Behavior and Human Performance 6(6): 649-744.

Statman, M., S. Thorley, and K. Vorkink. 2006. Investor overconfidence and trading volume. Review of Financial Studies 19(4): 1531-1565. https://doi.org/10.1093/rfs/hhj032.

Sun, Y., M. Wu, X. Zeng, and Z. Peng. 2021. The impact of COVID-19 on the Chinese stock market: Sentimental or substantial? Finance Research Letters 38: 101838.

Tabachnick, B.G., and L.S. Fidell. 2007. Using multivariate statistics, 5th ed. San Francisco: Allyn and Bacon.

Toma, F.M. 2015. Behavioral biases of the investment decisions of Romanian investors on the Bucharest stock exchange. Procedia Economics and Finance 32: 200-207.

Trinugroho, I., and R. Sembel. 2011. Overconfidence and excessive trading behavior: An experimental study. International Journal of Business and Management 6(7): 147.

Wang, Albert Y., and Michale Young. 2020. Terrorist attacks and investor risk preference: Evidence from mutual fund flows. Journal of Financial Economics 137: 49-514.

Wang, J., and X. Wang. 2019. Structural equation modeling: Applications using Mplus. John Wiley \& Sons.

Waweru, N.M., E. Munyoki, and E. Uliana. 2008. The effects of behavioural factors in investment decision-making: A survey of institutional investors operating at the Nairobi Stock Exchange. International Journal of Business and Emerging Markets 1(1): 24-41.

Wolf, E.J., K.M. Harrington, S.L. Clark, and M.W. Miller. 2013. Sample size requirements for structural equation models: An evaluation of power, bias, and solution propriety. Educational and Psychological Measurement 73(6): 913-934.

Wood, R., and J.L. Zaichkowsky. 2004. Attitudes and trading behavior of stock market investors: A segmentation approach. The Journal of Behavioral Finance 5(3): 170-179.

Worthington, R.L., and T.A. Whittaker. 2006. Scale development research: A content analysis and recommendations for best practices. The Counseling Psychologist 34(6): 806-838.

Yoong, J., and V.R.D.M. Ferreira. 2013. Improving financial education effectiveness through behavioural economics: OECD key findings and way forward. OECD Publishing 1: 1926-1982.

Zhang, Dayong, Min Hu, and Qiang Ji. 2020. Financial markets under the global pandemic of covid-19. Finance Research Letters 36: 101528 .

Zindel, M.L., T. Zindel, and M.G. Quirino. 2014. Cognitive bias and their implications on the financial market. International Journal of Engineering and Technology 14(3): 11-17.

Publisher's Note Springer Nature remains neutral with regard to jurisdictional claims in published maps and institutional affiliations. 